\title{
Simultaneous presentation of upper lobe fibrobullous disease and spinal pseudarthrosis in a patient with ankylosing spondylitis
}

\author{
M Hakala, E Kontkanen, O Koivisto
}

\begin{abstract}
A 51 year old man with a 20 year history of ankylosing spondylitis and pronounced thoracic gibbus presented with two simultaneous complications of longstanding ankylosing spondylitis, upper lobe fibrobullous disease, and spinal pseudarthrosis. No neurological sequelae developed and treatment was conservative. Both these lesions mimic tuberculosis, and so it is important to determine them accurately to avoid unnecessary antituberculosis treatment. Both of these complications are reported to occur in longstanding ankylosing spondylitis and their simultaneous presentation may be more common than is realised. This case is believed to be the first such report of their association.
\end{abstract}

Department of Internal Medicine, University of Oulu, Päivärinne Hospital, Muhos, Finland

M Hakala

E Kontkanen

O Koivisto

Correspondence to: Dr M Hakala, Päivärinne Hospital, SF-91410 Jokirinne, Finland Accepted for publication 19 October 1989

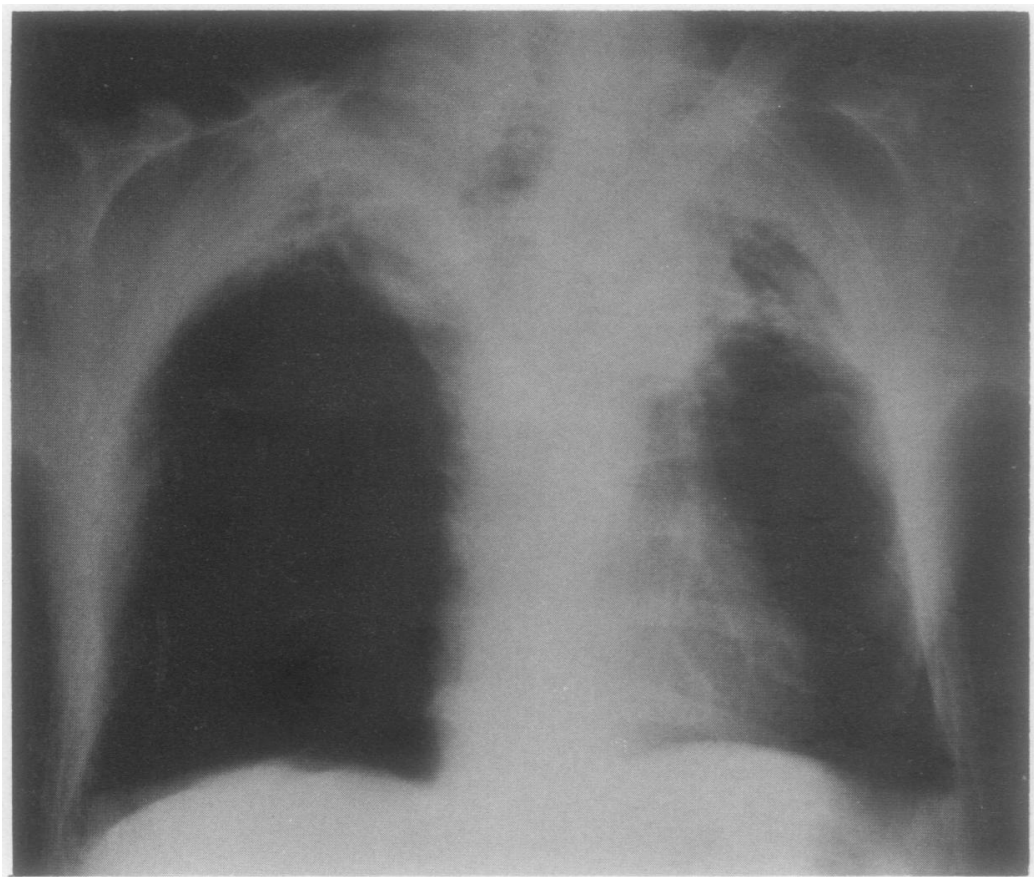

Figure 1 Chest $x$ ray picture showing fibrobullous disease at the apex of both lungs. multiple levels simultaneously and occurs during the early inflammatory phase of the disease..$^{13}$

Upper lobe fibrobullous disease is a well known manifestation of ankylosing spondylitis and mimics tuberculosis. ${ }^{4}$ About 100 cases had been reported up to $1977 . .^{5}$

We describe a man with a 20 year history of ankylosing spondylitis who had simultaneous spinal pseudarthrosis and upper lobe fibrobullous disease in both lungs. As far as we know, there has been no other published report of ankylosing spondylitis with the simultaneous presentation of these manifestations.

\section{Case report}

A 51 year old man who had had ankylosing spondylitis for 20 years was admitted to hospital in February 1987 because of apical shadowings in both his lungs. He had a history of hypertension and iritis. Except for breathlessness on effort he had no respiratory symptoms. Pains in the joints of the lower extremities, shoulders, and low- and mid-back were noted.

On admission he had muscle wasting, stiffened cervical, thoracic, and lumbar spine, and pronounced thoracic kyphosis. There was local tenderness over the thoracic gibbus. The movements of shoulder joints and right hip were restricted. No synovitis was found in peripheral joints. A slight systolic murmur was heard on cardiac auscultation and the breath sounds were faint. No neurological disturbances were found. Erythrocyte sedimentation rate was $77 \mathrm{~mm} /$ first hour, haemoglobin concentration was $127 \mathrm{~g} / \mathrm{l}$, leucocytes $12 \cdot 2 \times 10^{9} / 1$, thrombocytes $446 \times 10^{9} / 1$ and $C$ reactive protein concentration $68 \mathrm{mg} / \mathrm{l}$. A test for teichoic acid antibodies yielded negative results. A chest $x$ ray picture showed apical shadowings of both lungs (fig 1 ) and changes in thoracic spine. A tomogram of thoracic spine showed a destructive process of D11 and D12 (fig 2). Computed tomography was used to assist the taking of a needle biopsy specimen from the destructive spinal area. The specimen showed necrosis without signs of inflammation. Antituberculosis treatment with a combination of four drugs was started. Culture of sputum specimens for tuberculosis, however, remained negative. After eight months of treatment the antituberculosis drugs were stopped when no changes in the roentgenological findings were found. It was concluded that the pulmonary spinal changes were associated with the patient's ankylosing spondylitis.

In May 1989 he had further back pain, but had not shown any signs of spinal cord compression during the two years of follow up. His right hip required total endoprothesis replacement. 
Figure 2 (A) Lateral view of spinal lesion four years

before presentation (1983). (B) Tomogram of spinal lesion in 1987 showing pseudarthrosis and break through posterior ankylosed element.
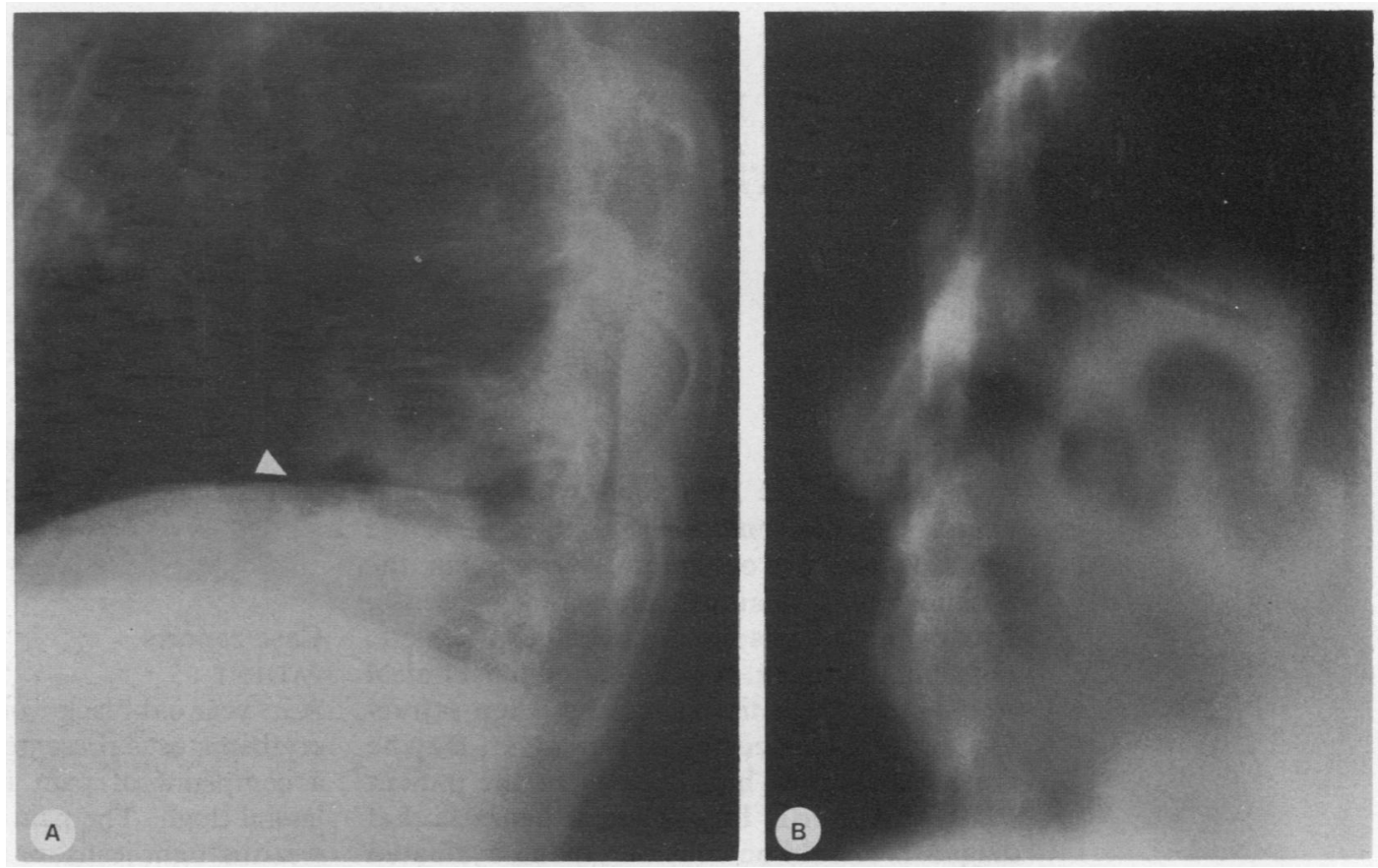

\section{Discussion}

Based on the roentgenological picture, lung tuberculosis and tuberculous spondylitis were initially suspected in our patient. Indeed, the upper lobe fibrobullous disease of ankylosing spondylitis may simulate tuberculosis ${ }^{5}$ and the spinal process, infective spondylitis. ${ }^{6}$ In our case bacteriological and antibody evidence of an infective process were absent and no response to chemotherapy was found. Paravertebral soft tissue masses, a feature of infectious spondylitis, were also absent.

Our patient was a typical case of spinal pseudarthrosis with longstanding ankylosing spondylitis and ankylosed spine ${ }^{17}$ with severe thoracic kyphosis. ${ }^{1}$ Chan et al proposed that an initiating event for spinal pseudarthrosis is posterior element weakness of the spine, though the anterior element osteolysis may be the more prominent roentgenological feature. ${ }^{1} \mathrm{~A}$ posterior bone defect could also be seen in our patient. He had neither neurological sequelae nor intolerable pain, and conservative treatment was justified. ${ }^{2}$
When patients with upper lobe fibrobullous disease also have longstanding ankylosing spondylitis its association with spinal pseudarthrosis (found in $15 \%$ of patients in a hospital series $^{1}$ ) may be fairly common.

1 Chan F L, Ho E K W, Fang D, Hsu L C S, Leong J C Y, Ngan H. Spinal pseudoarthrosis in ankylosing spondylitis. Acta Radiol [Diagn] (Stockh) 1987; 28: 383-8.

2 Jobanputra P, Kirkman B, Duke O, Crockard A. Discovertebral destruction in ankylosing spondylitis compli344-7.

3 Martel W. Spinal pseudoarthrosis. A complication of ankylosing spondylitis. Arthritis Rheum 1978; 21: 485-90.

4 Hunninghake G W, Fauci A S. Pulmonary involvement in the collagen vascular diseases. Am Rev Respir Dis 1979; 119: 471-503.

5 Rosenow III E C, Strimlan C V, Muhm J R, Ferguson R H. Pleuropulmonary manifestations of ankylosing spondylitis. Mayo Clin Proc 1977; 52: 641-9.

6 Good A E, Keller T S, Weatherbee L, Braunstein E M. Spinal cord block with a destructive lesion of the dorsal spine in ankylosing spondylitis. Arthritis Rheum 1982; 25: 218-22.

7 Cawley M I D, Chalmers T M, Kellgren J H, Ball J. Destructive lesions of vertebral bodies in ankylosing spondylitis. Ann Rheum Dis 1972; 31: 345-58. cated by spinal cord compression. Ann Rheum Dis 1988; 47: 